\title{
Title: Observing the Atlantic Meridional Overturning circulation yields a decade of inevitable surprises
}

\section{Srokosz \& H. Bryden}

\section{BACKGROUND}

A 2002 report Abrupt Climate Change: Inevitable Surprises? highlighted the North Atlantic circulation as possibly subject to abrupt change in a warming climate. Likewise the 2001 Intergovernmental Panel on Climate Change (IPCC) report suggested that the Atlantic meridional overturning circulation (AMOC) could weaken over the $21^{\text {st }}$ century. As this circulation carries heat northwards, giving the UK and northwest Europe a temperate climate, this generated renewed efforts to make observations of the AMOC. In particular, it led to the deployment of an observing system across the Atlantic at $26.5^{\circ} \mathrm{N}$ in spring 2004 , which last year achieved a decade of measurements.

\section{ADVANCES}

In addition to the baseline decade of $26.5^{\circ} \mathrm{N}$ observations, there have been other on-going measurements that capture components of the AMOC, some of which are not continuous or of much shorter duration. Together these observations are leading to a more complete picture of the AMOC. The $26.5^{\circ} \mathrm{N}$ AMOC observations have produced a number of surprises on time scales from sub-annual to multi-annual. First, the range of AMOC variability found in the first year, 4 to $35 \mathrm{~Sv}$ (Sverdrup = a million cubic meters per second, the standard unit for ocean circulation), was larger than the 15 to $23 \mathrm{~Sv}$ found previously from five ship-based observations over 50 years. A similarly large range to that at $26.5^{\circ} \mathrm{N}$ was subsequently been observed at $34.5^{\circ} \mathrm{S}$. Second, the amplitude of the seasonal cycle, with a minimum in the spring and a maximum in the autumn, was much larger ( $\sim 6.7 \mathrm{~Sv})$ than anticipated, and the driving mechanism of wind stress in the eastern Atlantic was unexpected too. Third, the $30 \%$ decline in the AMOC during 2009/10 was totally unexpected, and exceeded the range of inter-annual variability found in climate models used for the IPCC assessments. This event was also captured by Argo and altimetry observations of the upper limb of the AMOC at $41^{\circ} \mathrm{N}$. This dip was accompanied by significant changes in the heat content of the ocean, with potential impacts on weather that are the subject of active research. Finally, over the period of the $26.5^{\circ} \mathrm{N}$ observations, the $\mathrm{AMOC}$ has been declining at rate of about $0.5 \mathrm{~Sv}$ per year, ten 
times faster than predicted by climate models. Whether this is a trend, that is a decline due to global warming, or part of the so-called Atlantic Multi-decadal Oscillation / Variability, inferred from sea surface temperature measurement, is also a subject of active research. There is no doubt that continuously observing the AMOC over a decade has significantly altered our view of the role of ocean variability in climate.

\section{OUTLOOK}

The $26.5^{\circ} \mathrm{N}$ AMOC observations are stimulating the development of further AMOC observing systems both to the north, in the North Atlantic Subpolar Gyre, and to the south, in the South Atlantic. The aim is to obtain a holistic picture of the AMOC from south to north. Given the surprises and insights into the Atlantic circulation that observations have produced to-date, it is not too much to expect that with the new observations there will be future "inevitable surprises." 


\section{FIGURE}

A simplified schematic (top) of the Atlantic Meridional Overturning Circulation (AMOC. Warm water flows north in the upper ocean (red), gives up heat to the atmosphere (atmospheric flow gaining heat represented by changing color of broad arrows), sinks and returns as a deep cold flow (blue). Latitude of the $26.5^{\circ} \mathrm{N}$ AMOC observations is indicated. Note that the actual flow is considerably more complex. The ten year (April 2004 to March 2014) time series (bottom) of the AMOC strength at $26.5^{\circ} \mathrm{N}$ in Sverdrups $\left(1 \mathrm{~Sv}=10^{6} \mathrm{~m}^{3} \mathrm{~s}^{-1}\right)$. This is the 180 day filtered version of the time series. Visible are the low AMOC event in 2009/10 and the overall decline in AMOC strength over the ten year period.

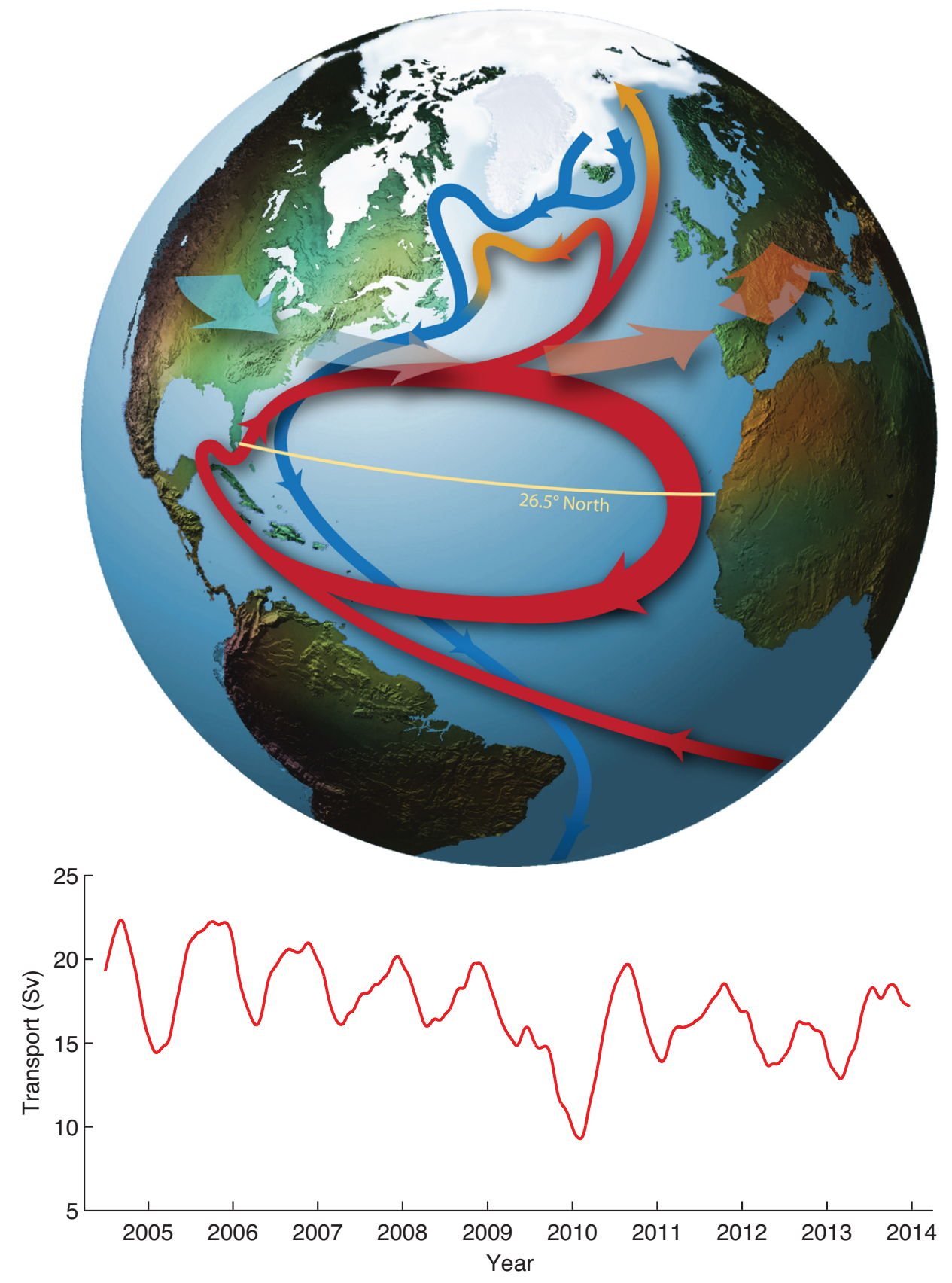

